\title{
Effect of fiber treatments on tensile and thermal properties of starch/ethylene vinyl alcohol copolymers/coir biocomposites
}

\author{
Morsyleide F. Rosa ${ }^{\mathrm{a}, \mathrm{b}}$, Bor-sen Chiou ${ }^{\mathrm{b}}$, Eliton S. Medeiros ${ }^{\mathrm{b}, \mathrm{c}}$, Delilah F. Wood ${ }^{\mathrm{b}}$, Tina G. Williams ${ }^{\mathrm{b}}$, \\ Luiz H.C. Mattoso ${ }^{\mathrm{c}}$, William J. Orts ${ }^{\mathrm{b}}$, Syed H. Imam ${ }^{\mathrm{b}, *}$ \\ ${ }^{a}$ Embrapa Agroindústria Tropical, Rua Dra Sara Mesquita, 2270, 60511-110, Fortaleza, CE, Brazil \\ ${ }^{\mathrm{b}}$ Bioproduct Chemistry and Engineering Research Unit, WRRC, ARS-USDA, Albany, CA 94710, USA \\ ${ }^{\mathrm{c}}$ Laboratório Nacional de Nanotecnologia para o Agronegócio, Embrapa Instrumentação Agropecuária, CP 741, 13560-970, São Carlos, SP, Brazil
}

\section{A R T I C L E I N F O}

\section{Article history:}

Received 12 September 2008

Received in revised form 12 March 2009

Accepted 12 March 2009

Available online 26 June 2009

\section{Keywords:}

Natural fibers

Coir fibers

Surface treatment

Biocomposites

Mechanical and thermal properties

\begin{abstract}
A B S T R A C T
Coir fibers received three treatments, namely washing with water, alkali treatment (mercerization) and bleaching. Treated fibers were incorporated in starch/ethylene vinyl alcohol copolymers (EVOH) blends. Mechanical and thermal properties of starch/EVOH/coir biocomposites were evaluated. Fiber morphology and the fiber/matrix interface were further characterized by scanning electron microscopy (SEM). All treatments produced surface modifications and improved the thermal stability of the fibers and consequently of the composites. The best results were obtained for mercerized fibers where the tensile strength was increased by about $53 \%$ as compared to the composites with untreated fibers, and about $33.3 \%$ as compared to the composites without fibers. The mercerization improved fiber-matrix adhesion, allowing an efficient stress transfer from the matrix to the fibers. The increased adhesion between fiber and matrix was also observed by SEM. Treatment with water also improved values of Young's modulus which were increased by about $75 \%$ as compared to the blends without the fibers. Thus, starch/EVOH blends reinforced with the treated fibers exhibited superior properties than neat starch/EVOH.
\end{abstract}

Published by Elsevier Ltd.

\section{Introduction}

The potential of biodegradable polymers and more specifically of biocomposites obtained from agro-resources have long been well established (Ashori, 2008; Bilba et al., 2007; Chiellini et al., 2001; Choudhury et al., 2007; Yang et al., 2003). Starch is one of the most studied and promising agro-resources for the production of biodegradable polymers as matrices for biocomposite applications. Starch, derivate from variety of botanical sources (cereals, legumes, and tubers), is widely available raw material for use in bioplastics (Bastioli et al., 1995; Kumar and Singh, 2008). However, due to starch's excessive hydrophilicity and brittleness, blending starch with conventional polymers is a promising approach to improve its drawbacks (Medeiros et al., 2008).

Starch/poly(ethylene vinyl alcohol) copolymer (EVOH) blends provide an interesting polymer system with a wide range of potential mechanical properties; however, the cost is still relatively high. Different kinds of lignocellulosic fibers have been investigated in blends for formulation of biocomposites (Coats et al., 2008; Corradini et al., 2006; Geethamma, 1998; Imam et al., 2005). The incorporation of these fibers as fillers or for reinforcement into blends

\footnotetext{
* Corresponding author. Tel.: +1 5105595794.

E-mail address: syed.imam@ars.usda.gov (S.H. Imam).
}

has received increased attention, particularly for price-driven and high volume applications.

Coir is an abundant, versatile, renewable, cheap, and biodegradable lignocellulosic fiber used for making a wide variety of products (Satyanarayana et al., 1982). Coir has also been tested as a filler or a reinforcement in different composite materials (Choudhury et al., 2007; Corradini et al., 2006; Geethamma, 1998; Owolabi et al., 1985). Furthermore, it represents an additional agroindustrial nonfood feedstock (agroindustrial and food industry waste) that should be considered as feedstock for the formulation of ecocompatible composite materials.

Several factors contribute to the production of fiber-composites with enhanced properties. Fiber-matrix has affected very strongly on the overall performance of the complete composite material (Franco and Valadez-González, 2005). Fiber-matrix interaction can be improved by surface or structural modification of the fibers using various processes such as alkali treatment, bleaching, acetylation and steaming (Corradini et al., 2006; Das et al., 2000; Hill and Abdul Khalil, 2000; Shukla and Pai, 2005).

One of most used modifications is the treatment with an alkali solution (Corradini et al., 2006; Prasad et al., 1983; Ray et al., 2001). The alkaline process, called mercerization, is an effective method that can improve the properties of composites reinforced with lignocellulosic fibers. Bleaching with hydrogen peroxide is 
another chemical treatment widely used in the textile industry that provides surface modification of the fibers (Rout et al., 2001; Salam, 2006).

The incorporation of treated coconut fibers into formulations with starch and EVOH can be a good alternative for producing low cost composites and possibly improving their mechanical properties. Thus, the main objective of the present investigation is to evaluate the influence of different fiber treatments, including washing with water, mercerization and bleaching on mechanical and thermal properties of extruded starch/EVOH blends loaded with the treated coir fibers. Additionally, the fiber/matrix interface was analyzed by using scanning electron microscopy (SEM).

\section{Experimental}

\subsection{Materials}

Midsol 50 native wheat starch (12\% moisture) was supplied by Midwest Grains, Inc. (Atchinson, KS). Poly(ethylene-co-vinyl alcohol) copolymer (EVOH) was provided by EVAL Company of America (Pasadena, TX) under the trade name EVAL-E105. This particular sample is a random copolymer with roughly 35\% ethylene copolymer. Glycerol was obtained from Sigma-Aldrich Corporation (St. Louis, MO). Unripe coconut fiber, from northeast Brazil, was provided by Embrapa Agroindústria Tropical (Fortaleza, CE, Brazil). These coconut fibers had high lignin content (40\%) and low cellulose contents (32\%).

\subsection{Coconut fiber treatments and mercerization}

All fibers were pre-washed with large amount of distilled water and dried at $50^{\circ} \mathrm{C}$ until constant weigh, prior to treatment. The mercerization process consisted of immersing coir fibers (200 g) in a $10 \%(\mathrm{w} / \mathrm{v})$ sodium hydroxide aqueous solution $(2 \mathrm{~L})$ for $3 \mathrm{~h}$ at $70{ }^{\circ} \mathrm{C}$ with occasional shaking followed by washing with distilled water several times to remove any absorbed alkali (Corradini et al., 2006).

\subsection{Bleaching}

Coconut fibers $(200 \mathrm{~g}$ ) were added to a $2 \mathrm{~L}$ solution containing $320 \mathrm{~mL}$ (30\%; w/w) hydrogen peroxide and $1 \mathrm{~g}$ sodium hydroxide at $85{ }^{\circ} \mathrm{C}$ and stirred for $1 \mathrm{~h}$. Subsequently, the material was washed thoroughly with water and dried in an oven at $50{ }^{\circ} \mathrm{C}$ until it has reached a constant weight (Katz, 1977; Rout et al., 2001; Shukla and Pai, 2005).

\subsection{Sample preparation}

Blends of thermoplastic starch (50\%; w/w), EVOH (30\%; w/w), water $(10 \% ; \mathrm{w} / \mathrm{w})$ and glycerol $(10 \% ; \mathrm{w} / \mathrm{w})$ as plasticizer were melting extruded with unripe coconut fibers. The weight of fibers in the composites was $15 \%$ of total weight of polymers (starch and $\mathrm{EVOH}$ ). The fibers were chopped in a knife mill and sieved through a 40-mesh sieve. Before extrusion, starch, EVOH and coconut fiber were premixed in a sealed ziplock bag and stored for $24 \mathrm{~h}$.

This mixture was introduced into a co-rotating twin-screw extruder (Leistritz Micro 18) with six heating zones whose temperatures were set at $85,95,105,115,110$, and $105^{\circ} \mathrm{C}$ from feed to die. The screws have a diameter of $18 \mathrm{~mm}$ and the barrel has a length to diameter ratio of 30:1. A K-Tron Soder T-20 loss-in-weight feeder was used to control the solids (starch-EVOH-fiber) feed rate. A
Bran + Luebbe N-P31 metering pump was used to control the liquid (glycerol-deionized water) feed rate. Following extrusion, the blended material was pelletized and injected into an injection molding machine (BOY 15S, screw diameter $=22 \mathrm{~mm}$, injection time $=7 \mathrm{~s}$, cooling time $=20 \mathrm{~s}$, mold dimensions: $73.5 \times 49 \times 1.5 \mathrm{~mm})$ at $150 \pm 1^{\circ} \mathrm{C}$.

\subsection{Tensile properties}

Tensile strength (TS), tensile modulus $(E)$ and elongation at break $(\varepsilon)$ were determined according to ASTM D3039, under ambient conditions, using an Instron 5500R Universal Testing Machine (Instron Corp., Canton, MA). Prior to testing, samples were equilibrated at $50 \%$ relative humidity in a chamber containing saturated solutions of calcium nitrate. The testing conditions used were: cross head speed of $5 \mathrm{~mm} / \mathrm{min}$ and load cell of $0.1 \mathrm{kN}$. Dumbbell samples $(1.5 \mathrm{~mm}$ thick) were tested with a gauge length of $20 \mathrm{~mm}$. The reported values are the average of at least 10 measurements.

\subsection{Thermal properties}

Thermogravimetric analysis (TGA) was performed under nitrogen atmosphere. The samples were heated from room temperature to $800{ }^{\circ} \mathrm{C}$ at a heating rate of $10^{\circ} \mathrm{C} / \mathrm{min}$ and a nitrogen gas flow rate of $60 \mathrm{~mL} / \mathrm{min}$. The derivative of TGA curves (DTG) was obtained using TA analysis software.

\subsection{Scanning electron microscopy (SEM) morphological characterization}

Coconut fiber was mounted onto aluminum specimen stubs using double-sided adhesive carbon tabs (Ted Pella, Redding, CA). In addition to the Instron-fractured surfaces, composite materials were also fractured in liquid nitrogen to observe the interior of the unstressed composite. A composite sample was dropped directly into liquid nitrogen and fractured with a pre-chilled razor blade held in a vice-grip. The fractured pieces were picked out of the liquid nitrogen using a pre-chilled forceps and placed in a desiccator to thaw to reduce the condensation of water on the surface of the material. All composite materials, fractured by the Instron Testing Machine and in liquid nitrogen, were mounted with the fractured surfaces facing up. All specimens were coated with Gold-Palladium for $45 \mathrm{~s}$ in a Denton Desk II sputter coating unit (Denton Vacuum USA, Moorestown, NJ). Specimens were viewed in a Hitachi S4700 field emission scanning electron microscope (Hitachi HTA, Japan) at $2 \mathrm{kV}$.

\subsection{Statistical analysis}

Statistical analysis included statistical hypothesis test (Student's $t$-test) to verify the existence of significant differences among the data at 95\% confidence level using Microsoft Office Excel 2003 software.

\section{Results}

The alkali treatment changed the color of the fibers from brown to dark brown and the bleaching with $\mathrm{H}_{2} \mathrm{O}_{2}$ produced yellowish brown fibers, indicating that the expected modification (removal of wax, fatty substances and lignin) might have been achieved, as demonstrated in works of other research groups (Katz, 1977; Rout et al., 2001). 
Table 1

Mechanical properties obtained by tensile tests with different coconut fiber treatments.

\begin{tabular}{lclc}
\hline Composite & TS (MPa) & $\varepsilon(\%)$ & $E(\mathrm{MPa})$ \\
\hline Starch/EVOH & $10.2 \pm 0.5^{\mathrm{a}}$ & $67 \pm 27^{\mathrm{a}}$ & $99 \pm 11^{\mathrm{a}}$ \\
Starch/EVOH/fiber (untreated) & $8.9 \pm 0.6^{\mathrm{b}}$ & $28 \pm 9^{\mathrm{b}}$ & $147 \pm 20^{\mathrm{b}}$ \\
Starch/EVOH/fiber (washed) & $11.2 \pm 1.2^{\mathrm{c}, \mathrm{a}}$ & $35 \pm 6^{\mathrm{c}, \mathrm{b}}$ & $172 \pm 30^{\mathrm{c}, \mathrm{b}}$ \\
Starch/EVOH/fiber $(\mathrm{NaOH})$ & $13.6 \pm 0.5^{\mathrm{d}}$ & $33 \pm 5^{\mathrm{d}, \mathrm{b}, \mathrm{c}}$ & $172 \pm 17^{\mathrm{d}, \mathrm{b}, \mathrm{c}}$ \\
Starch/EVOH/fiber $\left(\mathrm{H}_{2} \mathrm{O}_{2}\right)$ & $11.7 \pm 0.6^{\mathrm{e}, \mathrm{c}}$ & $31 \pm 5^{\mathrm{e}, \mathrm{b}, \mathrm{c}, \mathrm{d}}$ & $157 \pm 18^{\mathrm{e}, \mathrm{b}, \mathrm{c}}$
\end{tabular}

$\mathrm{TS}$, tensile strength; $\varepsilon$, elongation at break; $E$, tensile modulus.

Identical letters in the same column do not represent a significant difference at a 5\% level in the Student's $t$-test.

\subsection{Tensile tests}

Mechanical properties (TS, tensile strength; $\varepsilon$, elongation at break; and $E$, tensile modulus) of the composites containing different coconut fiber treatments are shown in Table 1.

Mechanical properties of composites were strongly influenced by adhesion between the matrix and fibers. The statistical analysis showed that the treatment with $\mathrm{NaOH}$ had the highest effect on tensile strength (TS) and tensile modulus (E), producing composites with the best tensile properties. The tensile strength of $\mathrm{NaOH}$-treated composites increased significantly by about $53 \%$ compared with composites made with untreated fiber and 33\% compared with composites without fiber (starch/EVOH). This is an indication that the mercerization conditions promoted good wettability and better fiber-matrix adhesion, allowing efficient stress transfer between the matrix and the fibers. Moreover, as reported by Mohanty et al. (2001), alkali treatment reduces fiber diameter and thereby increases the aspect ratio, improving mechanical characteristics of the composites.

This behavior has also been observed previously by other investigators. Prasad et al. (1983) studying composites made of polyester resin and coir fibers, obtained a $15 \%$ increase in tensile strength when fibers were soaked in a $5 \% \mathrm{NaOH}$ aqueous solution at $28^{\circ} \mathrm{C}$ for 72-76 h. Interfacial adhesion between coir and natural rubber was increased by treatment of the coir fibers with alkali (Geethamma, 1998). Similar results with alkali-treated coir fibers incorporated in gluten and glycerol-plasticized starch composites have been reported by Corradini et al. (2006).

The elongation at break $(\varepsilon)$ of the composites was not affected significantly by the different treatments when compared with composites made with untreated fibers. However, the addition of fiber either treated or untreated resulted in a decrease in value of $\varepsilon$ compared to blends without fibers.

As shown in Table 1, the elongation at break $(\varepsilon)$ of the starch/ EVOH blends decreased and tensile modulus $(E)$ increased considerably by approximately $74 \%$ with the incorporation of fibers, due to the rigid nature of the fibers reducing the ductile behavior of the composites. High elastic modulus composites are usually required in several important applications, such as in structural materials.
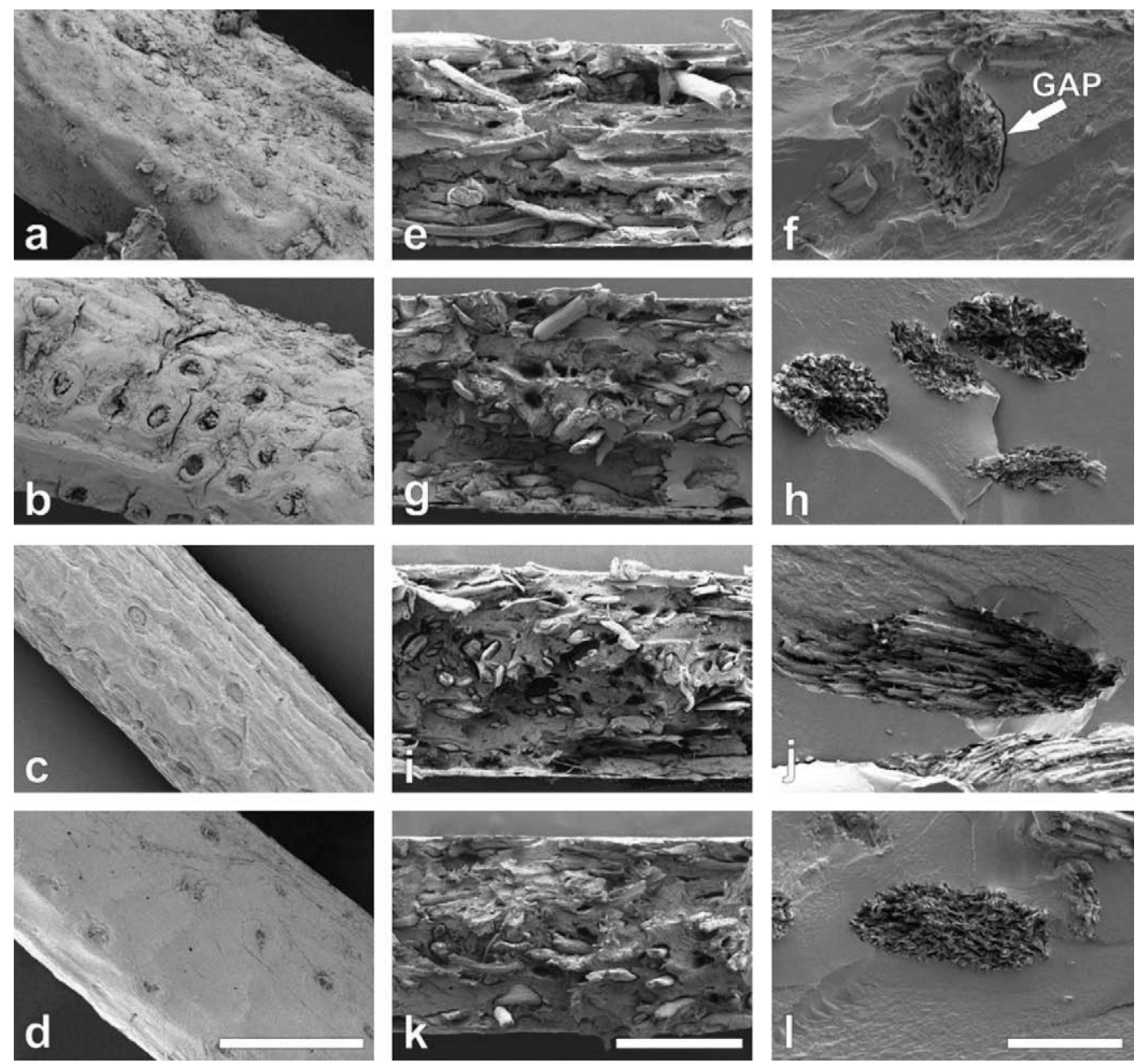

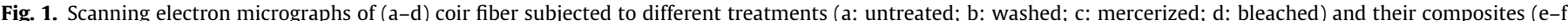

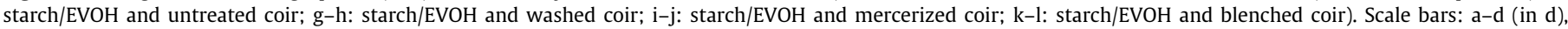
$50 \mu \mathrm{m}$; e, g, i and $\mathrm{k}$ (in k), $1 \mathrm{~mm}$; f, h, j and $\mathrm{l}$ (in l), $100 \mu \mathrm{m}$. 


\subsection{SEM morphological study}

The effects of the different treatments on the surface fiber and the adhesion between fibers and matrix were investigated by SEM. Fig. 1a-d shows SEM micrographs of untreated and treated coconut fibers and Fig. 1e-h shows SEM micrographs of fracture surfaces of starch/EVOH composites with different fiber treatments.

Coir fibers (Fig. 1a) contain impurities, wax, fatty substances and globular protrusions called "tyloses" (Rout et al., 2000). The fiber surfaces are extremely heterogeneous, with smooth and rough portions in the same fiber. The role of the treatment is mainly to remove these impurities of the natural coconut fiber, thus improving their wettability.
As can be seen in Fig. 1b, fiber washing was efficient in removing impurities; however, it did not remove the protrusions. Alkali treatment (Fig. 1c) removed fatty-deposits and tyloses leading to the formation of a rough surface with pits, resulting in mechanical anchorage and reduced pullout and gaps between the fiber and matrix in composite materials. Similar results were observed by Bismarck et al. (2001), Choudhury et al. (2007), Rahman and Khan (2007) and Rout et al. (2000) who reported that alkali treatment resulted in a higher amount of cellulose exposed on the fiber surface, thereby increasing the number of possible reaction sites.

Pits were not revealed on the surfaces of untreated fibers (Fig. 1a) and they were partly revealed on the surfaces of washed fibers (Fig. 1b). Bleaching with $\mathrm{H}_{2} \mathrm{O}_{2}$ (Fig. 1d) produced a smoother
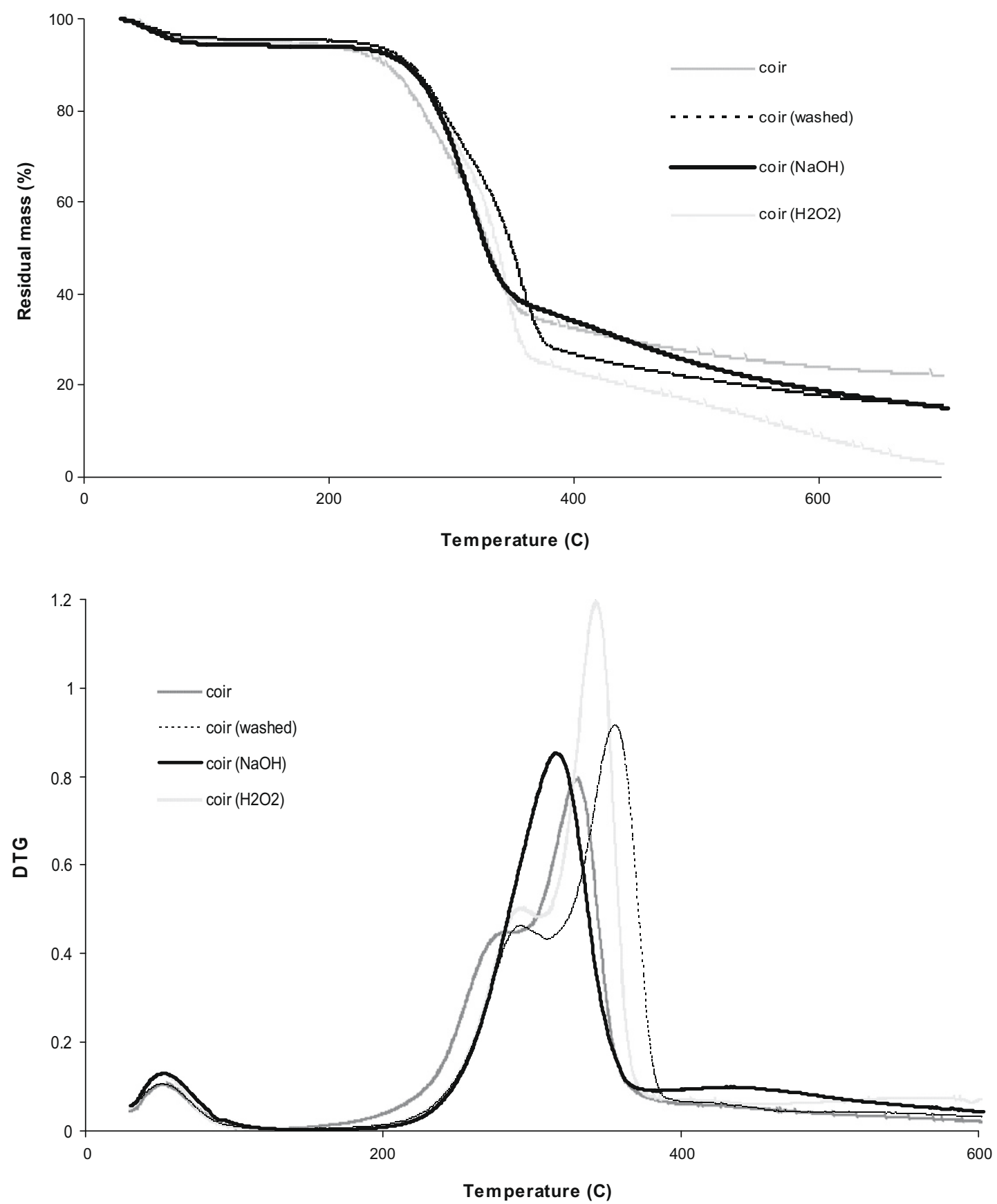

Fig. 2. TG and DTG curves obtained for coir fibers subjected to different treatments. 
Table 2

Thermogravimetric results for coir fibers subjected to different treatments.

\begin{tabular}{llcr}
\hline Coir fiber & $\begin{array}{l}\text { Transition } \\
\text { temperature range } \\
\left({ }^{\circ} \mathrm{C}\right)\end{array}$ & $\begin{array}{l}\text { Temperature of maximum rate } \\
\text { of weight loss }\left({ }^{\circ} \mathrm{C}\right)\end{array}$ & $\begin{array}{c}\text { Weigh } \\
\text { loss }(\%)\end{array}$ \\
\hline Untreated & $30-150$ & 53 & 5 \\
& $150-297$ & 285 & 25 \\
& $297-500$ & 330 & 43 \\
Washed & $30-150$ & 52 & 5 \\
& $155-315$ & 293 & 25 \\
& $315-500$ & 356 & 49 \\
$\mathrm{NaOH}$ & $30-150$ & 55 & 6 \\
& $160-500$ & 317 & 69 \\
& $-{ }^{*}$ & & 5 \\
$\mathrm{H}_{2} \mathrm{O}_{2}$ & $30-150$ & 53 & 25 \\
& $155-308$ & 292 & 54 \\
\hline
\end{tabular}

* Curve for alkaline treated fibers presents only two transitions.

surface. This dewaxed the fibers and improved the fiber/matrix adhesion (Fig. 1k and $\mathrm{l}$ ) to some extent, based on tensile tests.

It is clearly indicated in Fig. 1e-1, the variability in fiber-matrix adhesion for the treated and untreated composites. In the case of the untreated fibers (Fig. 1e and f), they seem to detach from the polymer matrix and have relatively large pull-outs compared to other treated fibers due to the poor interfacial adhesion with the matrix. This indicates higher interfacial shear strength for treated fibers and good interfacial adhesion between the fibers and matrix.

Moreover, as already mentioned, the literature reported that alkali treatment reduced fiber diameter and thereby increased the aspect ratio (Joseph et al., 1996; Varma et al., 1985). The immediate result of the treatments is that fibers increase their potential use as reinforcing agents for polymer composites.

\subsection{Thermal properties}

The results of thermogravimetric analyses for untreated and treated coir fibers are shown in Fig. 2 (TGA and DTG curves) and summarized in Table 2. It can be seen that the decomposition profiles of the fibers are characterized by three peaks. The first one is attributed to the evaporation of water and occurs between room temperature and $150^{\circ} \mathrm{C}$. The second step, which corresponds to hemicellulose degradation, starts at about $190^{\circ} \mathrm{C}$; and the third step occurs between 290 and $360^{\circ} \mathrm{C}$, corresponding to thermal degradation of cellulose. Lignin presents a broad peak throughout the range, degrading between 280 and $500{ }^{\circ} \mathrm{C}$ (Alvarez and Vázquez, 2004; Tomczac et al., 2007).

The treatments had a considerable effect on the thermal degradation behavior of the fibers, promoting an increase in the
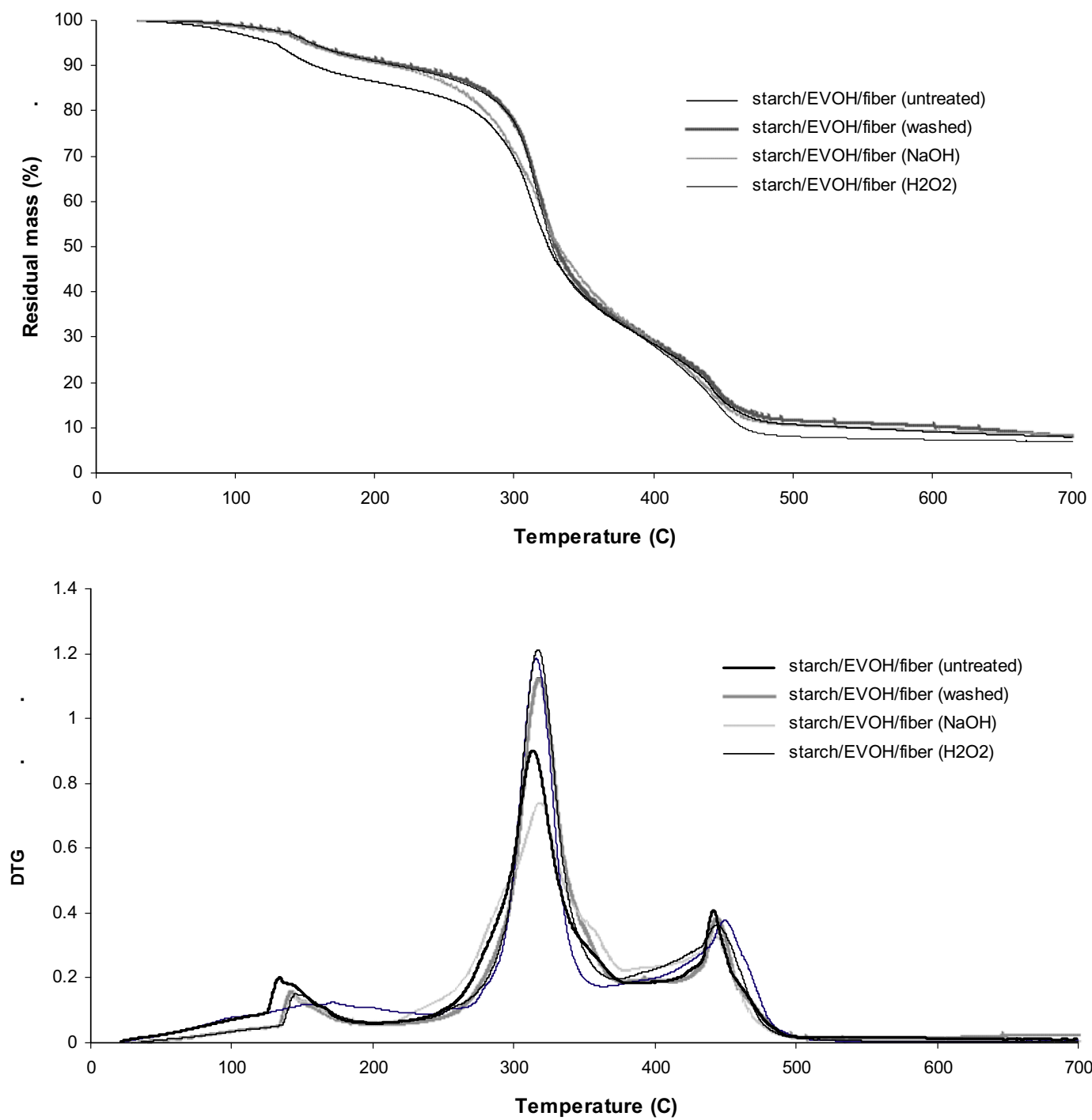

Fig. 3. TG and DTG curves for composites containing untreated and treated coir fibers. 
temperatures at which the thermal degradation took place. These changes can be interpreted in terms of removal of some easily hydrolyzed substances, which decompose earlier than the major components, cellulose and lignin, leading to higher thermal stability of the second step of degradation. The increase in thermal stability of alkali-treated coir fibers had also been reported earlier (Bismarck et al., 2001).

As reported in literature (Corradini et al., 2006; Valadez-González et al., 1999; Varma et al., 1986), surface treatments also partially dissolved lignin and hemicellulose present in the fiber, increasing the amount of exposed cellulose. Furthermore, some authors (Sreenivasan et al., 1996; Varma et al., 1986) reported that coir fibers changed their crystallinity through alkali treatment. According to Varma et al. (1986), upon alkali treatment, there was a partial loss of cementing material via the rupture of ester linkages between polyuronic acid and lignin, increasing the percentage of crystallinity index of alkali-treated fibers. This was corroborated by thermogravimetric analysis (TGA) data, where the curve for alkaline treated fibers did not present an inflection that was present in others. This might be due to a significant amount of hemicellulose being removed during the alkali treatment. The hemicellulose maximum degradation temperature in all the treated fibers showed a slight increase in value.

The thermal behavior of composites reinforced with treated and untreated fibers is shown in Fig. 3. Changes occurring in the fibers due to the treatments led to a positive effect on the thermal degradation behavior of the composites, as indicated by the higher thermal stability of the treated composites.

For the treated-coir composites, the moisture loss peak shifted towards higher temperatures, from $134{ }^{\circ} \mathrm{C}$ for the untreated fiber-composites to $142,143,145$, and $144^{\circ} \mathrm{C}$ for washed, $\mathrm{NaOH}$, and $\mathrm{H}_{2} \mathrm{O}_{2}$ fiber-reinforced composites, respectively. Similar results were found by Ray et al. (2004), investigating the thermal behavior of vinyl ester resin matrix composites reinforced with alkali-treated jute fiber. According to these authors, the tendency to release moisture at a higher temperature in the treated composites could be due to the improved wetting of the finely separated fibers by the matrix. The wetting produced a stronger bond at the interface and reduced the available surface area for moisture desorption, resulting in a delay in moisture evaporation. The hemicellulose degradation temperature increased slightly with treatment from $314^{\circ} \mathrm{C}$ for untreated fiber-composite to $318,317,317$, and $315^{\circ} \mathrm{C}$ for washed, mercerized and blenched fiber-reinforced composites, respectively.

\section{Conclusions}

The influence of fiber treatments by washing, mercerization and bleaching on the mechanical properties of starch/EVOH/coir biocomposites was analyzed. All the treatments removed surface impurities on fibers, producing modifications on the surface and improving thermal stability of both fibers and fiber-reinforced composites. Results were supported by SEM analyses.

Composites from treated coir fibers had better TS than those made from the untreated fibers, and improved values for TS and $E$, compared to blends without fibers. The composites made with mercerized fibers showed a considerable 33\% improvement in tensile strength and a $75 \%$ improvement in tensile modulus over that of the neat starch/EVOH blend.

Results indicate a better wettability of treated coir fibers with matrix and corroborated the role of treated coir fiber as not a filler, but as a reinforcing agent.

This research indicated that starch/EVOH blends reinforced with treated coconut fibers have superior characteristics when compared to pure starch/EVOH blends.

\section{Acknowledgements}

The authors wish to thank the financial and technical support given by EMBRAPA, Labex/program, CNPq, FINEP, CAPES, and ARS/USDA.

\section{References}

Alvarez, V.A., Vázquez, A., 2004. Thermal degradation of cellulose derivatives/starch blends and sisal fibre biocomposites. Polymer Degradation and Stability 84, 1321.

Ashori, A., 2008. Wood-plastic composites as promising green-composites for automotive industries. Bioresource Technology 99, 4661-4667.

Bastioli, C., Bellotti, V., Tredici, G.D., Ponti, R., 1995. Method of producing plasticized polyvinyl alcohol and its use for the preparation of starch-based, biodegradable thermoplastic compositions. US Patent Number 5,462,981.

Bilba, K., Arsene, M.-A., Ouensanga, A., 2007. Study of banana and coconut fibers: botanical composition, thermal degradation and textural observations. Bioresource Technology 98 (1), 58-68.

Bismarck, A., Mohanty, A.K., Aranberri-Askargorta, I., Czapla, S., Misra, M., Hinrichsenb, G., Springera, J., 2001. Surface characterization of natural fibers; surface properties and the water up-take behavior of modified sisal and coir fibers. Green Chemistry 3, 100-107.

Chiellini, E., Cinelli, P., Imam, S.H., Mao, L., 2001. Composite films based on biorelated agro-industrial waste and poly(vinyl alcohol). Preparation and mechanical properties characterization. Biomacromolecules 2, 1029-1037.

Choudhury, A., Kumar, S., Adhikari, B., 2007. Recycled milk pouch and virgin lowdensity. Polyethylene/linear low-density polyethylene based coir fiber composites. Journal of Applied Polymer Science 106, 775-785.

Coats, E.R., Loge, F.J., Wolcott, M.P., Englund, K., McDonald, A.G., 2008. Production of natural fiber reinforced thermoplastic composites through the use of polyhydroxybutyrate-rich biomass. Bioresource Technology 99 (7), 2680-2686.

Corradini, E., Morais, L.C., Rosa, M.F., Mazzetto, S.E., Mattoso, L.H., Agnelli, J.A.M., 2006. A preliminary study for the use of natural fibers as reinforcement in starch-gluten-glycerol matrix. Macromolecular Symposia 245-246, 558-564.

Das, S., Saha, A.K., Choudhury, P.K., Basak, R.K., Mitra, B.C., Todd, T., Lang, S., Rowell, R.M., 2000. Effect of steam pretreatment of jute fiber on dimensional stability of jute composite. Journal of Applied Polymer Science 76, 1652-1661.

Franco, PJH, Valadez-González, A., 2005. Fiber-matrix adhesion in natural fiber composites. In: Mohanty, A.K., Misra, M., Drzal, L.T. (Eds.), Natural Fibers, Biopolymers and Biocomposites. Taylor \& Francis, Florida, pp. 177-230.

Geethamma, V.G., 1998. Composite of short coir fibres and natural rubber: effect of chemical modification, loading and orientation of fibre. Polymer 39 (6-7), 1483-1497.

Hill, C.A., Abdul Khalil, H.P.S., 2000. Effect of fiber treatments on mechanical properties of coir or oil palm fiber reinforced polyester composites. Journal of Applied Polymer Science 78, 1685-1697.

Imam, S.H., Cinelli, P., Gordon, S.H., Chiellini, E., 2005. Characterization of biodegradable composite films prepared from blends of poly(vinyl alcohol), cornstarch, and lignocellulosic fiber. Journal of Polymers and the Environment 13 (1), 47-55.

Joseph, K., Thomas, S., Pavithran, C., 1996. Effect of chemical treatment on the tensile properties of short sisal fibre-reinforced polyethylene composites. Polymer 37 (23), 5139-5149.

Katz, J., 1977. Alkaline hydrogen peroxide bleaching method. Patent number $4,060,386$.

Kumar, A.P., Singh, R.P., 2008. Biocomposites of cellulose reinforced starch: improvement of properties by photo-induced crosslinking. doi:10.1016/ j.biortech.2008.04.045 (Available online 27 May 2008).

Medeiros, E.S., Dufresne, A., Orts, W.J., 2008. Starch-based nanocomposites. In: Bertolini, A., et al. (Eds.), Starches: Characterization, Properties, and Applications. CRC Press LLC (Chapter 8).

Mohanty, A.K., Misra, M., Drzal, L.T., 2001. Surface modifications of natural fibers and performance of the resulting biocomposites: an overview. Composite Interface 8 (5), 313-343.

Owolabi, O., Czvikovszky, T., Kovacs, I., 1985. Coconut-fiber-reinforced thermosetting plastics. Journal of Applied Polymer Science 30, 1827-1836.

Prasad, S.V., Pavithran, C., Rohatgi, P.K., 1983. Alkali treatment of coir fibres for coirpolyester composites. Journal of Materials Science 18, 1443-1454.

Rahman, M.M., Khan, M.A., 2007. Surface treatment of coir (Cocos nucifera) fibers and its influence on the fibers' physico-mechanical properties. Composites Science and Technology 67 (11-12), 2369-2376.

Ray, D., Sarkar, B.K., Rana, A.K., Bose, N.R., 2001. The mechanical properties of vinyl ester resin matrix composites reinforced with alkali-treated jute fibres. Composites: Part A 32, 119-127.

Ray, D., Sarkar, B.K., Basak, R.K., Rana, A.K., 2004. Thermal behavior of vinyl ester resin matrix composites reinforced with alkali-treated jute fibers. Journal of Applied Polymer Science 94, 123-129.

Rout, J., Tripathy, S.S., Nayak, S.K., Misra, M., Mohanty, A.K., 2000. Scanning electron microscopy study of chemically modified coir fibers. Journal of Applied Polymer Science 79 (7), 1169-1177.

Rout, J., Misra, M., Tripathy, S.S., Nayak, S.K., Mohanty, A.K., 2001. The influence of fibre treatment on the performance of coir-polyester composites. Composites Science and Technology 61, 1303-1310. 
Salam, M.A., 2006. Effect of hydrogen peroxide bleaching onto sulfonated jute fiber. Journal of Applied Polymer Science 99, 3603-3607.

Satyanarayana, K., Pillai, C.K.S., Sukumaran, K., Pillai, S.G.K., Rohatgi, P.K., Vijayan, K., 1982. Structure property studies of fibre from various parts of the coconut tree. Journal of Materials Science 17, 2453-2462.

Shukla, S.R., Pai, R.S., 2005. Adsorption of $\mathrm{Cu}(\mathrm{II}), \mathrm{Ni}(\mathrm{II})$ and $\mathrm{Zn}(\mathrm{II})$ on modified jute fibres. Bioresource Technology 96, 1430-1438.

Sreenivasan, S., Bhama Iyer, P., Krishna Iyer, K.R., 1996. Influence of delignification and alkali treatment on the fine structure of coir fibres (Cocos nucifera). Journal of Materials Science 31, 721-726.

Tomczac, F., Satyanarayana, K.G., Sydenstricker, T.H.D., 2007. Studies on lignocellulosic fibers of Brazil: Part II - morphology and properties of Brazilian coconut fibers. Composites: Part A, Applied Science and Manufacturing 38, 1710-1721.
Valadez-González, A., Cervantes-Uc, J.M., Olayo, R., Herrera-Franco, P.J., 1999. Effect of fiber surface treatment on the fiber-matrix bond strength of natural fiber reinforced composites. Composites: Part B 30, 309-320.

Varma, D.S., Varma, M., Varma, I.K., 1985. Coir fibres II: evaluation as a reinforcement in unsaturated polyester resin composites. Journal of Reinforced Plastics and Composites 4, 419-431.

Varma, D.S., Varma, M., Varma, I.K., 1986. Thermal behaviour of coir fibres. Thermochimica Acta 108, 199-210.

Yang, H.-S., Kim, D.J., Kim, H.J., 2003. Rice straw-wood particle composite for sound absorbing wooden construction materials. Bioresource Technology 86 (2), 117 121. 